\title{
Secreted protein acidic and rich in cysteine (SPARC) and vascular endothelial growth factor (VEGF) in endometrial cancer versus normal endometrial tissue
}

\author{
Raffaella Giannice $^{1 *}$ and Roberto Tozzi ${ }^{2}$ \\ ${ }^{1}$ Clinical Department of Obstetrics and Gynaecology, Istituti Clinici di Perfezionamento, Italy \\ ${ }^{2}$ Department of Gynaecologic Oncology, Oxford Cancer Centre, Churchill Oxford University Hospital, United Kingdom
}

\begin{abstract}
Objectives: Secreted Protein Acidic and Rich in Cysteine (SPARC), also termed osteonectin or BM-40, is a multifunctional calcium-binding matricellular glycoprotein, participating in tissue remodeling, morphogenesis, and bone mineralization. Furthermore, SPARC controls important mechanisms involved in cancer progression, including the regulation of angiogenesis. However, the function of SPARC in such phenomena is contradictory: in some studies SPARC was found to show tumor suppression and on the other hand, to have a protumorigenic and prometastatic action. Nowadays, the specific contribution of SPARC in tumor growth and progression is not completely assessed. In this study we decided to investigate, in human endometrial (EC) cancer versus normal endometrial counterpart (NE), the mRNA gene expression of SPARC and its correlation with VEGF mRNA expression in peritumoral microenvironment.
\end{abstract}

Material and methods: Fresh specimens from 15 patients with EC and corresponding NE were stored at $-80^{\circ} \mathrm{C}$. One mcg of mRNA was reverse-transcribed in cDNA. A Real-Time PCR determined relative cDNA levels of targeted gene mRNA.

Results: In EC vs NE, we observed a down-regulation of SPARC mRNA in $81 \%(\mathrm{P}<0.05)$ and a down-regulation of VEGF mRNA in $73 \%$ (P=NS) of samples. In EC, SPARC mRNA down-regulation was directly related to VEGF down regulation $(\mathrm{P}=0.003)$.

Conclusion: In endometrial cancer, under expression of SPARC is directly related to under-expression of $\mathrm{VEGF}(\mathrm{P}=0.003)$ and this result might be consistent with a SPARC function on tumor progression and invasion mediated by VEGF. Further studies, with a greater samples size needs to confirm this result.

\begin{abstract}
Abbreviations: SPARC: Secreted Protein Acidic and Rich in Cysteine; VEGF: Vascular Endothelial Growth Factor; EC: Endometrial cancer; NE: Normal endometrium; FIGO: International Federation of Gynecologic Oncology.
\end{abstract}

\section{Introduction}

Secreted Protein Acidic and Rich in Cysteine (SPARC), also termed osteonectin or BM-40, is a multifunctional calcium-binding matricellular glycoprotein, participating in tissue remodeling, morphogenesis, and bone mineralization and is secreted by many different types of cells, such as osteoblasts, fibroblasts, endothelial cells, and platelets [1-4]. Furthermore, SPARC controls important mechanisms involved in cancer progression, including the regulation of angiogenesis [4-5]. These mechanisms are relevant in the metastatic dissemination of several cancer cells, particularly into the bone tissue. However, the function of SPARC in such phenomena is controversial. In some studies SPARC was found to show a tumor suppressor [6]. On the other hand, SPARC can be described to have a protumorigenic and prometastatic action as reported in different human malignancies, such as coorectal, prostate, melanoma, hepatocellular, breast, lung and gastric cancer [7-16].

In human breast cancer, high SPARC expression might have utility as a prognostic marker [17]. Therefore nowadays, the specific contribution of SPARC in tumor growth and progression is not completely assessed [18]. SPARC has been found to reduce the activity of several growth factors, including VEGF. suggesting that SPARC might participate directly in tumor progression and invasion [19-20]. No reports in Literature assessed SPARC in human endometrial cancer. In this study we decided to analyze, in human endometrial cancer versus normal endometrial counterpart, the mRNA gene expression of SPARC and VEGF and their correlation in the peritumoral microenvironment.

\section{Materials and methods}

Immediately after surgery, fresh samples of endometrial cancer (EC) and their normal endometrial counterpart (NE) were obtained from patients submitted to primary surgery for endometrial cancer at RCCS Humanitas Clinical Institute in Milan (Italy). Parts of the samples were used for the histology diagnosis and other parts were immediately treated with RNA later (Ambion) for $24-36 \mathrm{~h}$ at $4^{\circ} \mathrm{C}$, and subsequently dried and stored at $80^{\circ} \mathrm{C}$. The study was approved by the Ethical Committee of Humanitas Research Institute and

*Correspondence to: Raffaella Giannice, Clinical Department of Obstetrics and Gynaecology, Istituti Clinici di Perfezionamento, Italy, Tel: 393384652855 ; E-mail: raffaella.giannice@asst-nordmilano.it

Key words: endometrial cancer, peritumor microenvironment, $m R N A$, secreted protein acidic and rich in cysteine, vascular endothelial growth factor

Received: October 14, 2020; Accepted: November 05, 2020; Published: November 09, 2020 
informed, written consent was obtained for all patients. All the clinical and surgical data were recorded on a data base. The total RNA was isolated both from endometrial cancer and normal endometrial specimen using TRI Reagent (Ambion). RNA was quantified by Nanodrop spectrophotometer ND-1000and its quality was examined by $1.5 \%$ agarose gel electrophoresis. According to the manufacturer's instructions, $1 \mathrm{mg}$ of total RNA was reverse-transcribed using the High-Capacity cDNA Archive kit (Applied Biosystems), treated with DNase I, quantified and re-verse - transcribed into cDNA using random primers. A real-time quantitative polymerase chain reaction, using Syber Green I (Applied Biosystem) as detection dye, was used to deter-mine the relative cDNA levels of genes in each samples. The ampli-fication protocol was used as following: $2 \mathrm{~min}$ at $50^{\circ} \mathrm{C}$ to activate uracil-DNA glycosylase, $10 \mathrm{~min}$ at $94.5^{\circ} \mathrm{C}$ (activation), 40 cycles of denaturation at $97^{\circ} \mathrm{C}$ for $30 \mathrm{~s}$ and annealing and extension at $59.7^{\circ} \mathrm{C}$ for $1 \mathrm{~min}$. The relative amount of each target gene mRNA to the housekeeping gene (18S) was calculated as 2(DCt), where DCt@ $\mathrm{Ct}$ gene ACt housekeeping gene. The fold-change of each tar-get gene mRNA to the corresponding normal tissue was calculated as 2(DDCt), where DDCt@DCt target gene in tumor tissue - DCt target gene in normal tissue. The threshold cycle $\mathrm{Ct}$ was automatically given by the SDS2.2 software package (Applied Biosystems).

We analyzed SPARC and VEGF gene expression in EC versus NE.

\section{Statistical analysis}

Statistical significance was determined by $\mathrm{T}$ - test and considered significant at a $\mathrm{P}$ value of $<0.05$.

\section{Results}

We collected tissue samples from endometrial cancer (EC) and from normal corresponding endometrium (NE) in 15 patients with endometrial cancer FIGO stage I-IIIC. All patients were submitted to primary laparoscopic total hysterectomy and bilateral salpingectomy with pelvic lymphadenectomy. Four patients dropped out from the study: two because the endometrial sample was damaged during the storage making it impossible to process, and two because no residual tumor was found in the samples, despite an initial histological diagnosis by endometrial biopsy. Tables 1 and 2 describe the clinical characteristics of the study population Three patients (27\%) underwent adjuvant chemotherapy and pelvic radiotherapy and one patient (9\%) underwent adjuvant pelvic radiotherapy (Table 2). At a median 3 years follow-up, the median disease-free survival was 25 months (range 18-36). Only one patient with clear cell adenocarcinoma

Table 1. Evaluable Patients' clinical characteristics

\begin{tabular}{|l|l|}
\hline No. of patients & 11 \\
\hline Median Age & $63($ range 53-81) \\
\hline Mediana BMI $\left(\mathrm{Kg} / \mathrm{m}^{2}\right)$ & $28($ range 25-31) \\
\hline FIGO stage I & $8(73 \%)$ \\
\hline IA & $7(64 \%)$ \\
\hline IB & $1(9 \%)$ \\
\hline FIGO stage III & $3(27 \%)$ \\
\hline III A & $2(18 \%)$ \\
\hline III C & $1(9 \%)$ \\
\hline Histotype & \\
\hline Endometrioid & $7(64 \%)$ \\
\hline Clear Cell & $2(18 \%)$ \\
\hline Villoglandular & $1(9 \%)$ \\
\hline Endometrioid with squamous differentiation & $1(9 \%)$ \\
\hline
\end{tabular}

BMI: Body Mass Index.
Table 2. Clinical characteristics of 11 evaluable patients

\begin{tabular}{|l|l|l|l|l|l|l|l|l|}
\hline Pt. & age & $\begin{array}{l}\text { FIGO } \\
\text { stage }\end{array}$ & LVS & N & G & Histotype & ADJ & $\begin{array}{l}\text { DFS } \\
\text { mnths }\end{array}$ \\
\hline 1 & 66 & IA & - & - & G3 & AE & FU* & 30 \\
\hline 2 & 65 & IA & - & - & G3 & ACC & PAC+RT & 32 \\
\hline 3 & 75 & IA & - & - & G1 & AV & FU & 36 \\
\hline 4 & 63 & IA & - & - & G2 & AE & FU & 35 \\
\hline 5 & 58 & IA & - & - & G2 & AE & FU & 23 \\
\hline 6 & 68 & IA & - & - & G2 & AE & FU & 24 \\
\hline 7 & 61 & IA & - & - & G2 & AE & FU & 36 \\
\hline 8 & 81 & IB & - & - & G2 & AE & FU & 22 \\
\hline 9 & 53 & IIIA & - & - & G2 & AS & PAC+RT & 25 \\
\hline 10 & 81 & IIIA & + & - & G2 & ACC & CT+RT & $18^{\circ}$ \\
\hline 11 & 63 & IIIC & + & + & G2 & AE & RT & 23 \\
\hline
\end{tabular}

LVS: Lymphovascular space; N: Lymph nodes; G: Histological grade; ADJ : Adjuvan therapy; DFS: Disease free survival in months; PAC: Cisplatin, Paclitaxel; CT: Carbo Taxol; RT: Radio Therapy; AE: Endometrioid Adenocarcinoma; ACC: Clear Cell Adenocarcinoma; AV: Villoglandular adenocarcinoma; AS: Squamous Adenocarcinoma; *: Patient refused RT; ${ }^{\circ}$ : Abdomino-pelvic relapse after 18 months.

FIGO stage IIIA and no residual disease after surgery relapsed at 18 months (Table 2).

In endometrial cancer versus normal counterpart, we observed that mRNA gene expression of SPARC was significantly down-regulated in $81 \%$ of samples (Figure. 1$),(\mathrm{P}<0.05)$ and mRNA gene expression of VEGF in $73 \%$ of samples (Figure. 2$)$, $(\mathrm{P}=\mathrm{NS})$. In endometrial cancer samples, we found that SPARC mRNA down-regulation was statistically significantly directly related to VEGF mRNA down-regulation (Figure. $3),(\mathrm{P}=0.003)$.

\section{Discussion}

This is the first report in Literature investigating SPARC mRNA expression in endometrial cancer fresh tissue and comparing it with VEGF mRNA expression. We chose the mRNA gene expression evaluation because during the transcription process, from cellular DNA to the final product, many mechanisms can interfere. Therefore we decided to evaluate the mRNA expression level of the two genes examined, as mRNA expression is the primary index of gene activity. Considering SPARC as a marker of metastasis and VEGF a marker of neo-vascularization, in our series of low risk endometrial cancer (mainly low risk histotype and early stage of disease) and considering that in literature in many cancers SPARC has been associated with progression disease, we expected a down regulation of SPARC mRNA expression. Similarly, angiogenesis, the formation of new blood vessels from preexisting vascular network, is essential to tumor growt and it is well known be mediated by VEGF. For this reason, as we expected in our study population cohort at low risk, we showed a down-regulation of VEGF mRNA, as we already described in an another report [21]. The statistical significant correlation between SPARC and VEGF in human endometrial microenvironment, might let us assume a precise interaction in endometrial cancer between these two mediators of tissue inflammation, repair and remodeling, as reported in Literature for gastric, breast and colon cancer [22-25]. Lastly, The statistical significant correlation between SPARC and VEGF down-regulation in human endometrial microenvironment, we can also hypothesize that SPARC can stimulate VEGF in endometrial cancer, favoring tumor metastases, but this theory needs to be confirmed by other type of investigations.

\section{Conclusion}

In endometrial cancer, under-expression of SPARC is directly related to under-expression of VEGF $(\mathrm{P}=0.003)$ and this result might be 
Giannice R (2020) Secreted protein acidic and rich in cysteine (SPARC) and vascular endothelial growth factor (VEGF) in endometrial cancer versus normal endometrial tissue

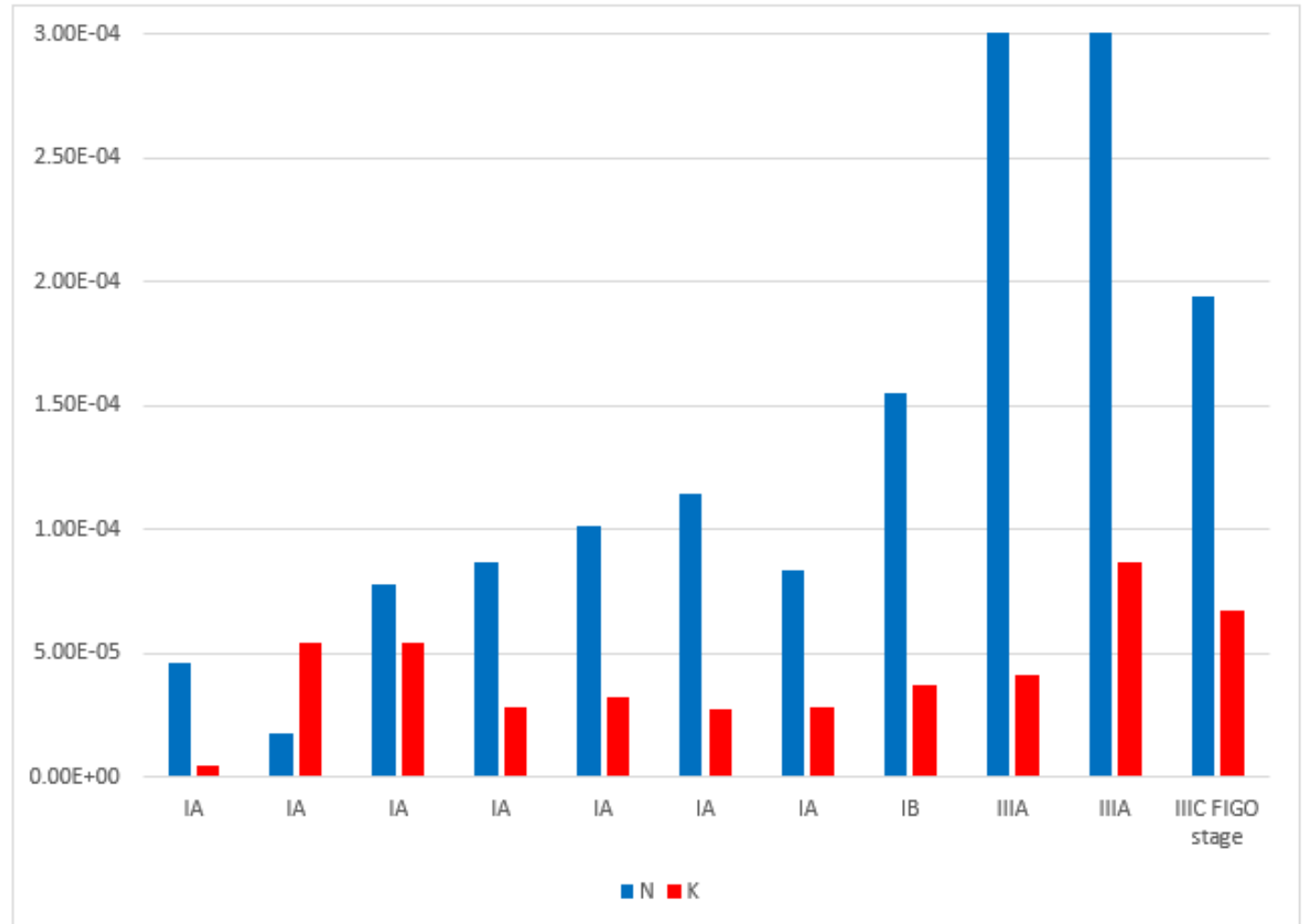

Figure 1. Secreted Protein Acidic and Rich in Cysteine (SPARC) mRNA gene expression in normal endometrium (N) versus endometrial cancer samples counterpart (K) In $91 \%$ Endometrial Cancer $(\mathrm{K})$ versus normal endometrium counterparts $(\mathrm{N})$ SPARC mRNA gene expression was down regulated. (P<0.05).

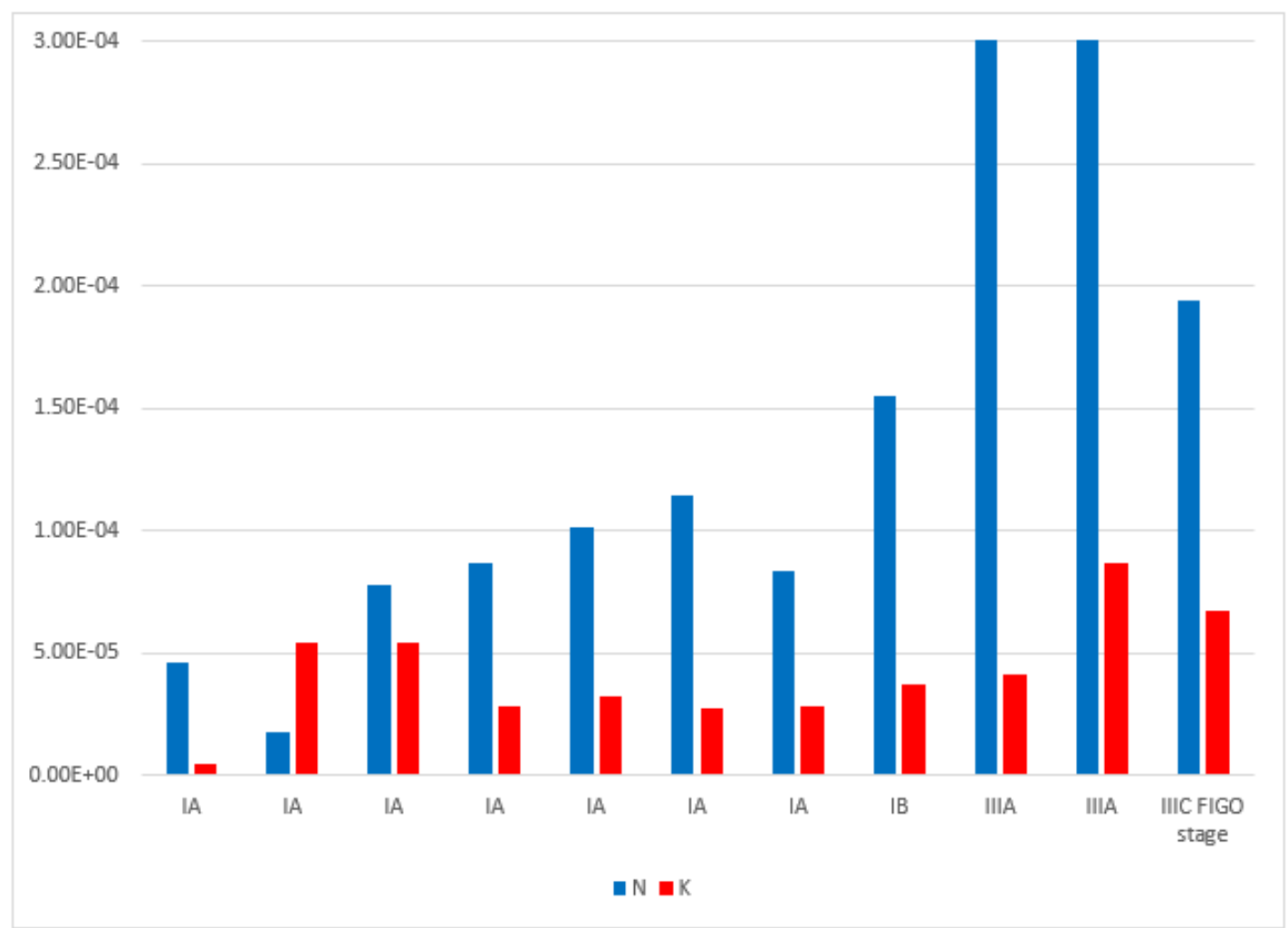

Figure 2. Vascular Endothelial Growth Factor (VEGF) mRNA gene expression in normal endometrium (N) versus endometrial cancer samples counterpart (K) In $73 \%$ endometrial cancer versus normal endometrium counterparts, VEGF mRNA gene expression was down- regulated (P=NS). 
Giannice R (2020) Secreted protein acidic and rich in cysteine (SPARC) and vascular endothelial growth factor (VEGF) in endometrial cancer versus normal endometrial tissue

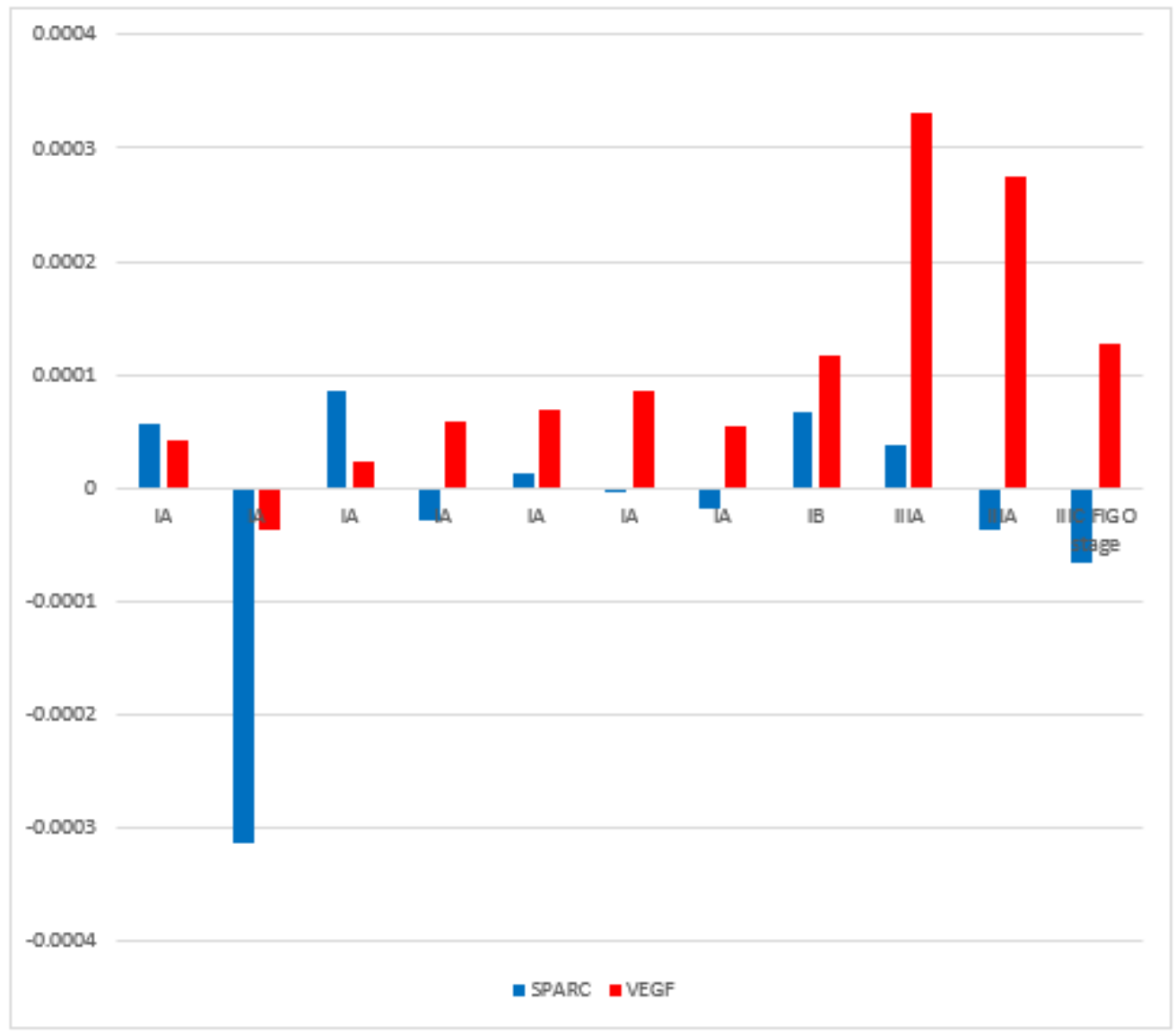

Figure 3. In endometrial cancer samples, correlation between VEGF mRNA and SPARC mRNA down-regulation In $73 \%$ SPARC mRNA expression was directly related to VEGF mRNA expression $(\mathrm{P}=0.03)$.

consistent with a SPARC function on tumor progression and invasion through VEGF expression. Further studies, with a greater samples size needs to confirm this result.

\section{Acknowledgements}

Our thanks to Paola Allavena, MD, PhD and Marco Erreni, $\mathrm{PhD}$.

\section{Conflict of interest}

No conflicts of interest.

\section{Funding}

No sources of funding.

\section{References}

1. Termine JD, Kleinman HK, Whitson SW, Conn KM, McGarvey ML, et al. (1981) Osteonectin, a bone-specific protein linking mineral to collagen. Cell 26: 99-105.

2. Brekken RA, Sage EH (2001) SPARC, a matricellular protein: at the crossroads of cellmatrix communication. Matrix Biol 19: 816-827.

3. Alford AI, Hankenson KD (2006) Matricellular proteins: Extracellular modulators of bone development, remodeling, and regeneration. Bone 38: 749-757.

4. Sage EH, Reed M, Funk SE, Truong T, Steadele M, et al. (2003) Cleavage of the matricellular protein SPARC by matrix metalloproteinase 3 produces polypeptides that influence angiogenesis. J Biol Chem 278: 37849-37857.

5. Nagaraju GP, Dontula R, El-Rayes BF, Lakka SS (2014) Molecular mechanisms underlying the divergent roles of SPARC in human carcinogenesis. Carcinogenesis 35: 967-973.
6. Brekken RA, Puolakkainen P, Graves DC, Workman G, Lubkin SR, et al. (2003) Enhanced growth of tumors in SPARC null mice is associated with changes the ECM. J Clin Invest 111: 487-495.

7. Porte H, Chastre E, Prevot S, Nordlinger B, Empereur S, et al. (1995) Neoplastic progression of human colorectal-cancer is associated with overexpression of the stromelysin-3 and BM-40/SPARC genes. Int J Cancer 64: 70-75.

8. Robert G, Gaggioli C, Bailet O, Chavey C, Abbe P, et al. (2006) SPARC represses E-cadherin and induces mesenchymal transition during melanoma development. Cancer Res 66: 7516-7523.

9. Riggs J, Chamboredon S, Castellazzi M, Kerry JA, Bos TJ (2002) Transcriptiona upregulation of SPARC, in response to c-Jun overexpression, contributes to increased motility and invasion of MCF7 breast cancer cells. Oncogene 21: 7077-7091.

10. Atorrasagasti C, Malvicini M, Aquino JB, Alaniz L, Garcia M, et al. (2010) Overexpression of SPARC obliterates the in vivo tumorigenicity of human hepatocellular carcinoma cells. Int J Cancer 126: 2726-2740.

11. Porte H, Chastre E, Prevot S, Nordlinger B, Empereur S, Basset P, et al. (1995) Neoplastic progression of human colorectal cancer is associated with overexpression of the stromelysin-3 and BM-40/SPARC genes. Int J Cancer 64: 70-75.

12. Koukourakis MI, Giatromanolaki A, Brekken RA, Sivridis E, Gatter KC, et al. (2003) Enhanced expression of SPARC/osteonectin in the tumor-associated stroma of nonsmall cell lung cancer is correlated with markers of hypoxia/acidity and with poor prognosis of patients. Cancer Res 63: 5376-5380.

13. Wang CS, Lin KH, Chen SL, Chan YF, Hsueh S (2004) Overexpression of SPARC gene in human gastric carcinoma and its clinic-pathologic significance. $\mathrm{Br} J$ Cancer 91: 1924-1930.

14. Yin J, Chen G, Liu Y, Liu S, Wang P, et al. (2010) Downregulation of SPARC expression decreases gastric cancer cellular invasion and survival. $J$ Exp Clin Cancer Res 29: 59. 
15. Zhao ZS, Wang YY, Chu YQ, Ye ZY, Tao HQ (2010) SPARC is associated with gastric cancer progression and poor survival of patients. Clin Cancer Res 16: 260-268.

16. Thomas R, True LD, Bassuk JA, Lange PH, Vessella RL (2000) Differential expression of osteonectin/SPARC during human prostate cancer progression. Clin Cancer Res 6: 1140-1149.

17. Graham JD, Balleine RL, Milliken JS, Bilous AM, Clarke CL (1997) Expression of osteonectin mRNA in human breast tumours is inversely correlated with oestrogen receptor content. Eur J Cancer 33: 1654-1660.

18. Arnold SA, Brekken RA (2009) SPARC: A matricellular regulator of tumorigenesis. $J$ Cell Commun Signal 3: 255-273.

19. Funk SE, Sage EH (1991) The Ca 2+ binding glycoprotein SPARC modulates cellcycle progression in bovine endothelial-cells. Proc Natl Acad Sci USA 88: 2648-2652.

20. Tremble PM, Lane TF, Sage EH, Werb Z (1993) SPARC, a secreted protein associated with morphogenesis and tissue remodeling, induces expression of metalloproteinases in fibroblasts through a novel extracellular matrix-dependent pathway. $J$ Cell Biol 121: 1433-1444.
21. Giannice R, Erreni M, Allavena P, Buscaglia M, Tozzi R (2013) Chemokines mRNA expression in relation to the Macrophage Migration Inhibitory Factor (MIF) mRNA and Vascular Endothelial Growth Factor (VEGF) mRNA expression in the microenvironment of endometrial cancer tissue and normal endometrium: a pilot study. Cytokine 64: 509-515.

22. Bawazeer S, Sabry D, Mahmoud RH, Elhanbuli HM, Yassen NN, et al. (2018) Association of SPARC gene polymorphisms rs3210714 and rs7719521 with VEGFexpression and utility of Nottingham Prognostic Index scoring in breast cancer in a sample of Egyptian women. Mol Biol Rep 45: 2313-2324.

23. Liang JF, Wang HK, Xiao H, Li N, Cheng CX, et al. (2010) Relationship and prognostic significance of SPARC and VEGF protein expression in colon cancer. J Exp Clin Cancer Res 29: 71.

24. Paley PJ, Goff BA, Gown AM, Greer BE, Sage EH (2000) Alterations in SPARC and VEGF immunoreactivity in epithelial ovarian cancer. Gynecol Oncol 78: 336-341.

25. Zhang JL, Chen GW, Liu YC, Wang PY, Wang X, et al. (2012) Secreted protein acidic and rich in cysteine (SPARC) suppresses angiogenesis by down-regulating the expression of VEGF and MMP-7 in gastric cancer. PLoS One 7: e44618.

Copyright: $\odot 2020$ Giannice R. This is an open-access article distributed under the terms of the Creative Commons Attribution License, which permits unrestricted use, distribution, and reproduction in any medium, provided the original author and source are credited. 